\title{
HLA B27 and the genetics of ankylosing spondylitis
}

\author{
J. C. WOODROW, AND C. J. EASTMOND
}

From the Department of Medicine, Liverpool University

SUMMARY One hundred and twenty-eight of 145 patients with ankylosing spondylitis (AS) were found to be HLA B27 positive. Five patients had evidence of a sero-negative peripheral arthritids resembling peripheral psoriatic arthritis and 3 of these were B27 negative. One further B27 negatiog patient had a sister with ankylosing spondylitis and ulcerative colitis and a mother with ulceratike colitis. There was evidence of a somewhat later age of onset of symptoms in B27 negative patient These findings are interpreted as suggesting some degree of clinical and genetic heterogeneity i⿱ i⿱ ankylosing spondylitis with genes for psoriasis and inflammatory bowel disease being important some individuals, particularly those who are B27 negative.

Twenty-five first-degree relatives with ankylosing spondylitis were all B27 positive. The only instance of disassociation of B27 and spondylitis in a family was where the proband had ulcerative colitis as well as spondylitis. Of 13 B27 positive fathers 3 could be diagnosed as having definife ankylosing spondylitis $(23 \%)$. These findings are thought to provide evidence against the concegt that the gene for ankylosing spondylitis is not B27 but a closely linked gene and favour the occu品 rence of an environmental event affecting approximately one-fifth of B27 positive males to regutt in disease.

The finding by Brewerton et al. (1973) and Schlosstein et al. (1973) of a markedly increased frequency of HLA B27 in patients with ankylosing spondylitis raises important questions concerning the genetics and pathogenesis of this disorder. The aims of the present study were to examine the relationship of B27 to ankylosing spondylitis by studying a series of patients to determine (1) if there was evidence of clinical and genetic heterogeneity in ankylosing spondylitis, (2) if dissociation of ankylosing spondylitis from B27 occurs in families, and (3) the prevalence of ankylosing spondylitis in first-degree relatives of B27 positive probands.

\section{Patients and methods}

Patients were consecutively included in the series after clinical and radiological assessment resulting in a diagnosis of definite ankylosing spondylitis as judged by the New York criteria (Bennett and Wood, 1968). Patients who were found to have psoriasis or inflammatory bowel disease or patients with spondylitis who had been ascertained through a study of patients with uveitis were excluded. Histocompati- bility antigen typing was performed in these patien and in 451 controls who were blood donors members of staff, using a standard microlymph $\Theta$ cytoxicity technique (Terasaki and McClellan震 1964).

\section{FAMILY STUDIES}

These can be divided into 3 separate studies. TI first was selective, in which relatives suspected having a relevant rheumatic disease from the histo 9 . given by the proband were examined clinically ang radiologically and HLA typed.

The second was a clinical, radiological, and HLA typing study of parents of $20 \mathrm{HLA} \mathrm{B27}$ positive probands, where both parents were alive and acces? sible. In addition, the parents of 2 further HLA B 2 positive patients with ankylosing spondylitis ascepo tained because of uveitis were included. Parents were chosen for this study as all were over the age of 45 years and it is unlikely that evidence of ankylosing spondylitis will appear for the first time after this age.

Thirdly, 3 identical twins of patients with ank losing spondylitis were examined, and the results have been previously reported (Eastmond and Woof row, 1977). 


\section{Results}

\section{HLA TYPING}

One hundred and twenty-eight of the 145 probands $(88.3 \%)$ were HLA B27 positive, the control frequency being $8.97 \%$. Twenty-two of the patients were female of whom $1(4.5 \%)$ was B27 negative compared with 16 of the 122 males ( $13 \%$ ). A history of acute anterior uveitis was obtained in 22 patients $(15.9 \%)$ of whom 16 were male and all were B27 positive with the exception of one male patient.

\section{PATIENTS WITH PERIPHERAL ARTHROPATHY} One B27 positive male patient had, in addition to ankylosing spondylitis, sero-positive erosive peripheral rheumatoid arthritis with a histologically confirmed rheumatoid nodule over the left olecranon process.

Two male B27 positive patients had a history of previous Reiter's disease occurring several years before the onset of the symptoms of spondylitis.

Five patients had a sero-negative peripheral small joint arthropathy with features similar to those seen in patients with peripheral psoriatic arthropathy, 2 being B27 positive and 3 negative. The 2 B27 positive patients both gave a history of 'sausage toes' and 1 of these, who previously had onycholysis of some of the finger nails but no skin lesions, has more recently developed a small skin lesion on the right knee suggestive of psoriasis.

The 3 B27 negative patients in this category are of considerable interest. One had had episodes of 'sausage fingers' and some swelling of proximal interphalangeal joints and later developed swan-neck deformity of several fingers with minimal erosive changes radiologically. The second patient has had swelling and tenderness of interphalangeal joints of the toes and his father has psoriasis with similar changes in the toes and a proximal interphalangeal joint arthropathy in the hands but no radiological sacroiliitis. The third patient has had an asymmetrical distal and proximal interphalangeal joint arthropathy of the hand with erosive changes in the clinically affected joints.

Two B27 positive female patients have had a mild peripheral small joint oligoarthritis with no distinctive features in respect of joints affected or clinical features of the joint involvement.

\section{HLA B27 NEGATIVE PATIENTS}

Three of these 17 patients are documented above. Two other patients in this group are of interest. One male developed symptoms of ankylosing spondylitis at the age of 32 years and at the age of 62 years developed an acute synovitis of wrists, metacarpophalangeal joints, and ankles with associated circinate balanitis, keratodermia blenorrhagicum of the palms and soles, and conjunctivitis but no urethritis or diarrhoea. This episode resolved leaving no residua. The second patient, also male, and whose parents were first cousins had a sister with ankylosing spondylitis and ulcerative colitis and a mother with ulcerative colitis and probable ankylosing spondylitis. (Fig. 1).

The 12 remaining B27 negative patients differed in no way clinically or radiologically from the B27 positive patients. Six of these were of considerable clinical severity with radiological changes in the spine as well as in the sacroiliac joints.

AGE OF ONSET (Fig. 2)

It was possible to determine the approximate age of onset with some reasonable accuracy in 137 patients. The distribution of the age of onset in B27 negative patients was compared with that in the B27 positive patients by the Wilcoxon rank sum test. It was found that the age of clinical onset in B27 negative patients was higher overall than that in the B27 positive patients $(\mathrm{P}=0 \cdot 012)$.

\section{FAMILY ST UDIES}

\section{Selected families}

In the families of 22 probands all of whom were B27 positive there were 2 or more cases of ankylosing spondylitis. Four of these probands were female. All 25 clinically affected relatives of these probands were B27 positive. The only instance where an affected relative of a B27 negative proband was found is shown in Figure 1.

Figure 3 shows a family not included within the main series because the B27 negative proband had ulcerative colitis in addition to ankylosing spondylitis

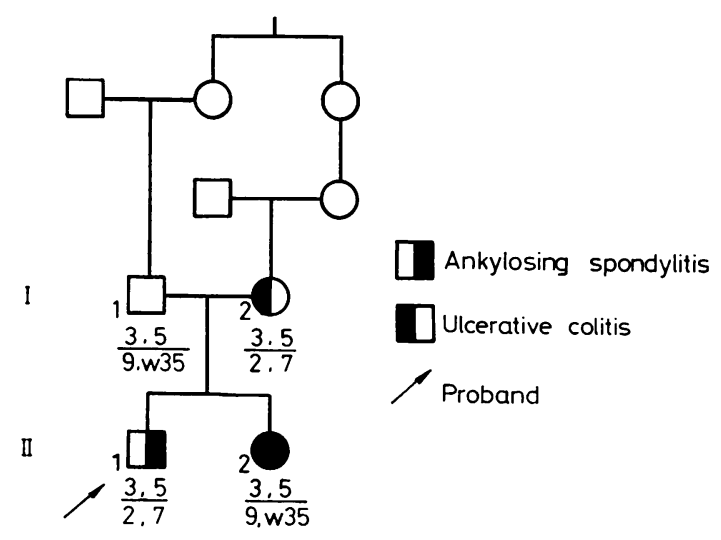

Fig. 1 Pedigree of the family of a B27 negative patient with ankylosing spondylitis. 

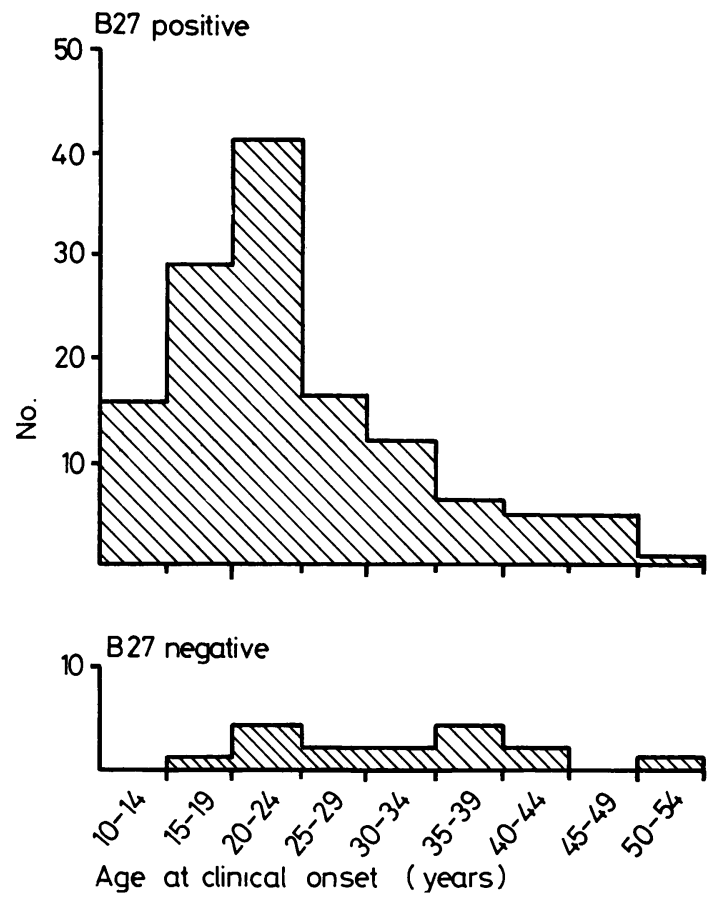

Fig. 2 Distribution of age at onset of symptoms in $B 27$ positive and B27 negative patients with ankylosing spondylitis.

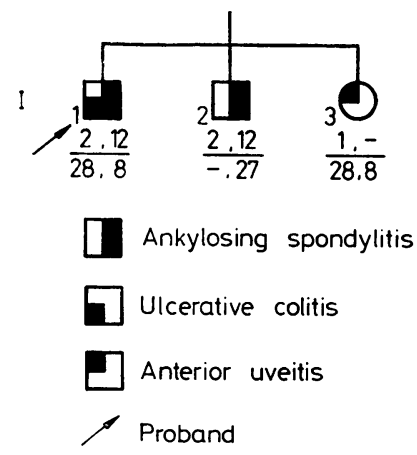

Fig. 3 Pedigree of the family of a B27 negative patient with ankylosing spondylitis and ulcerative colitis showing an affected $B 27$ positive proband.

A brother was found to be B27 positive and had ankylosing spondylitis and a sister was B27 negative and gave a history of acute anterior uveitis. This was the only example encountered in the study of 2 first-degree relatives with spondylitis, one being B27 positive and the other negative.
Study of parents

Thirteen of the 22 fathers and 12 of the 22 mothers of 22 HLA B27 positive probands were found to HLA B27 positive. Of these parents, 2 fathers wero known to have clinical and radiological ankylosiris spondylitis and 1 father had asymptomatic grade radiological sacroiliitis and spondylitis with limite spinal movements and diminished chest expansiou Two fathers had asymptomatic grade 3 radiologic 8 sacroiliitis. Thus 3 out of $13(23 \cdot 1 \%)$ B27 positive fathers could be diagnosed as having ankylosing spondylitis. No clinical or radiological evidence of disease was found in the HLA B27 positive mothe or in the HLA B27 negative parents.

\section{Identical twins}

A study of 2 identical twins of probands with anky losing spondylitis revealed no clinical or radiologica evidence of ankylosing spondylitis or related diseas? Their ages were 45 and 52 years, respectively. The identical twin aged 59 of a further patient with severe ankylosing spondylitis had a history of 1 episode of acute anterior uveitis and radiologically had a un\& lateral grade 3 sacroiliitis but no rheumatic symptoms (Eastmond and Woodrow, 1977).

\section{Discussion}

The association between ankylosing spondylitis ând HLA B27 raises two main and related questions The first is whether the major gene underlying susceptibility to the disease (the AS gene) is $B 20$ itself or whether it is not B27 but a gene which is at⿳⺈ locus very close to the HLA B locus and which is in very strong linkage disequilibrium with B2F

The second and related question is whether the spondylitis in B27 negative individuals is genetical the same as in $\mathbf{B} 27$ positive subjects, ie that the AS gene is the same for both groups and is therefore nof B27.

\section{B27 ITSELF versus LINKED AS GENE}

A strong possibility in regard to most HLA and disease associations is that the disease susceptibilit gene may not be the particular HLA A or B locus genes found to be associated with the disease but are genes at closely linked loci in linkage disequilibriur with the A and B locus genes. However, the relative risk for ankylosing spondylitis in B27 positive individuals when estimated from combined data 76 (Woodrow, 1977), this being considerably highet than for any other HLA and disease association.

If the HLA linked AS gene were not B27 itself twe findings might be expected. The first is that aggregq tion of B27 negative individuals with spondylitf should occur in families to the same degree as is observed in the case of B27 positive patients. So far 
no pair of B27 negative first-degree relatives with spondylitis appears to have been documented. The only instance we have observed is the family shown in Fig. 1 in which ulcerative colitis was present in 1 of the 2 affected B27 negative sibs and in their mother. It is of interest that the parents in this family were related, suggesting the possibility of a recessive trait predisposing to the inflammatory bowel disease and spondylitis. Another interesting family in which a B27 negative spondylitic was the offspring of a consanguinous marriage was reported by Van der Linden et al., (1975).

Secondly, one might expect to see examples of disassociation of B27 from ankylosing spondylitis within a family, ie, evidence of recombination between the B locus and the supposed locus for the AS gene. Two families have been reported (Dick et al., 1975; Strosberg et al., 1975) in which apparent disassociation of spondylitis from B27 has occurred. In these instances genetic recombination would be the explanation if it were certain that other, nonHLA linked genes predisposing to spondylitis were not segregating in the families.

The only occasion on which this phenomenon was observed in the present study was in a family shown in Fig. 3 where the B27 negative patient with spondylitis also had ulcerative colitis.

The demonstration of genetic recombination classically depends on the certain identification of the presence or absence of relevant segregating genes and thus it is relatively easy for traits showing simple Mendelian inheritance, ie, the presence of a particular phenotype must imply the presence of one particular gene. This does not necessarily apply to conditions with a possible heterogeneous genetic basis and where the trait does not invariably appear in the genetically predisposed.

Further information on this point may be obtained by studying the prevalence of ankylosing spondylitis in B27 positive persons in the general population compared with B27 positive relatives of ankylosing spondylitis probands. Evidence has been produced that something of the order of $20 \%$ of B27 positive individuals develop ankylosing spondylitis in some degree (Calin and Fries, 1975; Truog et al., 1975; Cohen et al., 1976). It is of interest to compare this figure with that for the incidence of disease in B27 positive first-degree relatives of B27 positive probands. If indeed the $20 \%$ incidence claimed is the true figure for the general population it could arise in three main ways. The first is that the AS gene is B27 and a separate gene segregating independently of the HLA system and present in homozygous or heterozygous state (depending on whether the effect is as a recessive or dominant trait) is also necessary to produce the complete genotype for the disease. If this were true one would expect that, for a dominant interacting gene, $50 \%$ of first-degree $\mathrm{B} 27$ positive relatives would develop spondylitis and, for a recessive trait, approximately $25 \%$ of $\mathrm{B} 27$ positive sibs and a considerably lower frequency of parents would develop disease. Secondly, B27 might be the AS gene and an environmental factor randomly affecting $20 \%$ of the population is necessary for the disease to develop. This would result in a similar prevalence of disease in B27 positive relatives of probands as in B27 positive persons in the general population, ie $20 \%$, unless these relatives are more liable to be exposed to an important environmental agent. The third possibility is that the AS gene is not B27 but is present on approximately $20 \%$ of chromosomes which have the B27 gene. In this case all B27 positive first-degree relatives would be expected to have this gene and to develop disease to some degree.

The finding of ankylosing spondylitis in $23.1 \%$ of B27 positive fathers in the present study may be compared with the figure given above for the general population. The fact that these are of a similar order is strongly against a linked AS gene on $20 \%$ of B27 positive chromosomes, and is most in keeping with the result expected with the second proposal of a random environmental factor affecting $20 \%$ of the population. However, this approach requires further investigation using identical criteria for the study of the general population and the families. Discordance in identical twins is also supportive evidence for environmental factors affecting the prevalence of disease in genetically predisposed individuals.

The absence of clinical and radiological abnormalities in any of the B27 positive mothers studied so far supports previous general experience of the sex distribution of the disease and is difficult to reconcile with the findings of Calin and Fries (1975) who in their study of a population of B27 positive individuals found approximately equal numbers of males and females with evidence of spondylitis.

\section{B27 POSITIVE SPONDYLITIS versus}

B27 NEGATIVE SPONDYLITIS

In regard to the previous discussion it is of some interest to know if there is evidence for heterogeneity within the disease ankylosing spondylitis, as this may have a bearing on the way we may attempt to determine the nature of the AS gene.

\section{CLINICAL EVIDENCE}

It has been suggested that the disease takes a milder and more localised course in B27 negative patients. Thus Möller and Olhagen (1975) found all 66 patients with radiologically demonstrable syndesmophytes to be $\mathrm{B} 27$ positive, in contrast with $70 \%$ of 60 patients 
with sacroiliitis as the only radiological manifestation. Feldmann et al. (1975) found 6 B27 negative patients amongst 25 with milder disease and only 1 of 25 with moderate or severe disease. However, Van den Berg-Loonen et al. (1977) found 4 of 20 patients with spinal involvement to be B27 negative and Jeannet et al. (1975) found 3 B27 negative patients among 14 females with radiological involvement of the spine. In the present series the 17 B27 negative patients had clinical and radiological involvement as severe as was found in the B27 positive patients. One possibility is that patients with sacroiliitis only are aetiologically more heterogeneous than those with spinal changes and it is of interest that Dekker-Saeys et al. (1978) described 11 patients with ulcerative colitis who had asymptomatic radiological sacroiliitis and of these only 1 was B27 positive.

With regard to peripheral arthritis, 3 of the B27 negative patients in the present study had an arthropathy with features strongly suggestive of psoriatic arthropathy but in the absence of psoriasis. It has been shown that patients with psoriatic peripheral arthritis and ankylosing spondylitis are less frequently B27 positive than patients with ankylosing spondylitis alone (reviewed in Woodrow, 1977). The implication is that genes for psoriasis may be playing a role in the pathogenesis of spondylitis in these cases, a conclusion also drawn from a study of the arthropathies occurring in patients with psoriasis (Eastmond and Woodrow, 1977).

The fact that B27 negative patients tend to have a somewhat higher age of onset of symptoms supports the thesis of aetiological heterogeneity between the two groups.

As mentioned above, no examples of ankylosing spondylitis occurring in 2 B27 negative relatives has been reported previously. The only example seen by us was a family in which there could be genes for ulcerative colitis predisposing to the development of ankylosing spondylitis. This explanation is supported by the fact that patients with ulcerative colitis and ankylosing spondylitis are less frequently B27 positive than those with ankylosing spondylitis alone (Brewerton et al., 1974). The family shown in Fig. 3 also gives credance to this argument. The brother without ulcerative colitis could be considered as dependent upon being B27 positive in order to develop ankylosing spondylitis whereas the proband with ulcerative colitis was able to develop equally severe spinal disease in the absence of B27.

\section{CONCLUSIONS}

(1) Present evidence favours the gene for ankylosing spondylitis being the HLA B27 gene itself and the results of present study would be against the linke⿻ gene hypothesis.

(2) There is some evidence that ankylosing spondyen? litis is genetically heterogeneous and that in HL B27 negative persons it differs from the disease if HLA B27 positive persons by (a) having a later mear age of onset, (b) having, in some cases, features of psoriatic peripheral arthritis, and (c) having, if some cases, evidence for genes for ulcerative coliti\& predisposing to spinal disease.

(3) The present study does not support the $\operatorname{sug}_{\overline{0}}$ gestion that ankylosing spondylitis is less severe in HLA B27 negative patients than HLA B27 positiv $\overrightarrow{e_{2}}$ ones, when no associated disease is present.

ASSOCIATION WITH OTHER ARTHROPATHIES The single case of sero-positive rheumatoid arthritio is considered to represent the coincident occurrencer of the separate conditions in the same individual The two instances where Reiter's disease had occurred before the onset of symptoms of spondylitis probably represent the occurrence of two diseases provoked in the same genetically predisposed indiê viduals by different environmental agents. Instance where Reiter's disease occurred in patients wh $\Phi$ already had ankylosing spondylitis have been ppe viously reported (Woodrow et al., 1974).

\section{References}

Bennett, P. H., and Wood, P. H. N. (1968). Population studies of the rheumatic diseases. In Proceedings of th Third International Symposium. 1st ed., p. 456. Excerpt@ Medica Foundation: Amsterdam.

Brewerton, D. A., Caffrey, M., Nicholls, A., Walters, D. and James, D. C. O. (1974). HL-A 27 and arthropathies associated with ulcerative colitis and psoriasis. Lancet, 956-958.

Brewerton, D. A., Hart, F. D., Nicholls, A., Caffrey, Mఖ James, D. C. O., and Sturrock, R. D. (1973). Ankylosing spondylitis and HL-A 27. Lancet, 1, 904-907.

Calin, A., and Fries, J. F. (1975). Striking prevalence of ankylosing spondylitis in "healthy" W27 positive male and females. New England Journal of Medicine, 293, 835-839.

Cohen, L. M., Mittal, K. K., Schmid, F. R., Rogers, L. F 요 and Cohen, K. L. (1976). Increased risk for spondylitis stigmata in apparently healthy HL-AW27 men. Annals Inernal Medicine, 84, 1-7.

Dekker-Saeys, B. J., Meuwissen, S. G. M., Van den Berg N Loonen, E. M., de Haas, W. H. D., Agenant, D., and Tytgat, G. N. J. (1978), Ankylosing spondylitis and inflammatory bowel disease. II. Prevalence of peripherato arthritis, sacroiliitis and ankylosing spondylitis in patients suffering from inflammatory bowel disease. Annals of the Rheumatic Diseases.

Dick, H. M., Sturrock, R. D., Goel, G. K., Henderson, N\$ Canesi, B., Rooney, P. J., Dick, W. C., and Buchanan, W. W. (1975). The association between HL-A antigensत्र ankylosing spondylitis and sacroiliitis. Tissue Antigens, 5 26-32. 
Eastmond, C. J., and Woodrow, J. C. (1977). The HLA system and the arthropathies associated with psoriasis. Annals of the Rheumatic Diseases, 36, 112-120.

Feldmann, J. L., Amor, B., Kahan, A., Solnick, C., and Delbarre, F. (1975). Antigene HL-A W27 interet diagnostique en rhumatologie. Revue du Rhumatisme, 42 , 85-92.

Jeannet, M., Saudan, Y., and Bitter, T. (1975). HL-A27 in female patients with ankylosing spondylitis. Tissue Antigens, 6, 262-264.

Möller, E., and Olhagen, B. (1975). Studies on the major histocompatibility system in patients with ankylosing spondylitis. Tissue Antigens, 6, 237-246.

Schlosstein, L., Terasaki, P. I., Bluestone, R., and Pearson, C. M. (1973). High association of an HL-A antigen, W27, with ankylosing spondylitis. New England Journal of Medicine, 288, 704-706.

Strosberg, J. M., Allen, F. H., Jr., Calabro, J. J., and Harris, E. D., Jr. (1975). Ankylosing spondylitis in a large kindred: clinical and genetic studies. Tissue Antigens, 5, 205-212.
Terasaki, P. I., and McClelland, J. D. (1964). Microdroplet assay of human serum cytotoxins, Nature, 204, 998-1000. Truog, P., Steiger, U., Contu, L., Galfre, G., Trucco, M., Bernoco, D., Bernoco, M., Birgen, I., and Ceppellini, R. (1975). Ankylosing spondylitis (AS): A population and family study using HL-A serology and MLR. In Histocompatibility Testing, p. 788, ed. by F. Kissmeyer-Nielsen. Munksgaard: Copenhagen.

Van denBerg-Loonen, E. M., Dekker-Saeys, B. J., Meuwissen, S. G. M., Nijenhuis, L. E., and Engelfriet, C. P. (1977). Histocompatibility antigens and other genetic markers in ankylosing spondylitis and inflammatory bowel diseases. Journal of Immunogenetics, 4, 167-175.

Van Der Linden, J. M. J. P., Keuning, J. J., Wuisman, J. H. C., Cats, A., and Van Rood, J. J. (1975). HL-A 27 and ankylosing spondylitis, Lancet, 1, 520.

Woodrow, J. C. (1977). Histocompatibility antigens and rheumatic diseases. Seminars in Arthritis and Rheumatism, 6, 257-276.

Woodrow, J. C., Treanor, B., and Usher, N. (1974). The HL-A System in Reiter's syndrome. Tissue Antigens, 4, 533-540. 